\section{Gregor Jenuš}

Ministerium für Kultur

der Republik Slowenien,

Archiv der Republik Slowenien
UDK 323.15(497.412=112.2)(091)

DOI: $10.4312 /$ linguistica.60.2.257-279

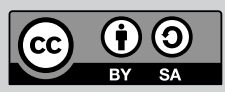

\title{
DIE VERGESSENE MINDERHEIT: ZUR GESCHICHTE DER DEUTSCHEN IN MARIBOR
}

\section{EINLEITUNG}

Die Geschichte Maribors ist geprägt von Auseinandersetzungen zwischen Deutschen und Slowenen. Bis zum Zerfall der österreichisch-ungarischen Monarchie war Maribor (Marburg an der Drau) (wie auch die beiden anderen großen urdeutschen Städte in der Untersteiermark - Ptuj (Pettau) und Celje (Cilli)) eine deutsche Sprachinsel in mitten eines slowenischen Siedlungsgebietes. Die Städte und Märkte in der Untersteiermark waren vor dem Ersten Weltkrieg vom Anschein her deutsche Ortschaften; sie waren Zentren des politischen, wirtschaftlichen und kulturellen Lebens, in denen Deutsch gesprochen wurde. Die rurale Umgebung war hingegen slowenisch. Angesichts der Beispiele aus anderen slawischen Teilen der Monarchie hatten Ende des 19. Jahrhunderts Slowenen angefangen, Forderungen nach Anerkennung ihrer Kultur und Sprache zu stellen, vor allem in den Schulen und Ämtern. Diese Forderungen wurden abgelehnt und bildeten somit im Laufe der nächsten Jahrzehnte den Kern der politischen Programme slowenischer Parteien, mit denen sie die Bewölkung auf ihre Seite ziehen wollten (Bauer 1907: 95-97, 144-149; Schneefuss 1939: 11; Zwitter 1962: 32, 47; Puff 1999: 293; Zwitter 1955: 163-164; Jenuš 2011a: 8). In der politischen Propaganda wurden die „herrschenden“ Deutschen als Unterdrücker der Slowenen dargestellt, die Slowenen hingegen von der Gegenseite als undankbare Unruhestifter.

\section{ZWISCHEN DER LOYALITÄT ZUM KAISER UND DEM WUNSCH DER SLOWENEN NACH NATIONALER AUTONOMIE}

Der Erste Weltkrieg machte die Situation nicht erträglicher. Im Gegenteil, die 1914 eingeführten Militärgesetze und Einschränkungen hatten die Nationalitätenkämpfe in der Untersteiermark sogar noch zugespitzt. Eifersüchtig wachten Vertreter beider Nationalitäten über die ,gerechte“ Verteilung der Lasten (Pleterski 1980: 7; Svoljšak 2005: 109-127; Svoljšak 2009: 300, 301; Jenuš 2011a: 40, 41; Jenuš 2015: 307). Die Slowenen erwarteten, dass ihnen die Regierung wegen der immensen Verluste und Opfer für das Vaterland wenigstens jetzt Gehör schenken würde. Dies geschah aber nicht.

*gregor.jenus@gov.si 
Der Krieg brachte dem slowenischen Volk bittere Enttäuschungen, deren Folgen noch nicht beurteilt werden können. Unmittelbar nach dem Beginn des Krieges wurde das slowenische Volk von den Zivil- und Militärbehörden mit allen Mitteln verfolgt und aufs schlimmste gedemütigt. Und das alles ohne wirklichen Grund: diese Verfolgung stammt entweder aus den tiefsten Gefühlen des Misstrauens und des Bösen gegenüber unserem Volk, oder von völligen Unkenntnis unserer Situation. / . . / Das slowenische Volk leidet und kämpft für seine Heimat, aber es stellt sich die Frage, warum der Staat, den es für den Preis seines eigenen Blutes verteidigt und seinen Besitz opfert, angesichts einer solchen Schande nicht fähig ist, für sein loyales Volk zu sorgen.

Dieser Auszug stammt aus der ersten Interpellation des Jugoslawischen Klubs im Wiener Parlament im Juni 1917 (Pleterski 1971: 30-31).

Die Slowenen hatten genug: Südslawische Politiker, vereint im Jugoslawischen Klub, nutzten im Frühjahr 1917 die erneute Einberufung des Wiener Parlamentes aus und äußerten ihre Forderungen. Im Namen des Jugoslawischen Klubs las Dr. Anton Korošec auf der Parlamentssitzung am 30. Mai 1917 die Forderung nach der Neugestaltung der Donaumonarchie vor und verlangte die nationale Autonomie der Slowenen, Kroaten und Serben, die in ihr lebten. Die Slowenen (bzw. Südslawen) waren es leid als Staatsbürger zweiter Klasse betrachtet zu werden (Bister 1990: 76-79). In der sogenannten Mai-Deklaration gaben die jugoslawischen Politiker bekannt (Žerjav 1917: 5; Bister 1995: 217-221), dass sie:

/.../auf Grundlage des nationalen Rechts und des kroatischen Staatsrechts die Vereinigung aller Länder der Donaumonarchie, in denen Slowenen, Kroaten und Serben leben, in einen selbstständigen Staatsapparat fordern, der nach den Demokratischen Prinzipien unter dem Zepter der Habsburg-Lothringen Dynastie geformt ist. ${ }^{1}$

Die Mai-Deklaration wurde von der Regierung mit Empörung aufgenommen und als ein offener Angriff auf das Fortbestehen der Doppelmonarchie angesehen. Trotzdem aber gab es den Anschein, dass niemand in den Regierungsstellen wirklich an eine Realisierung dieser Forderungen glaubte. Das passive Verhalten der Wiener Regierungskreise war für die untersteirischen Deutschen unverständlich. Nach Meinung der untersteirischen deutschen Zeitungen hatte sich die Atmosphäre im Staat gedreht und sich zu einer offensichtlichen Erpressung von Seiten der südslawischen Politiker gewendet. Die Zeitung Deutsche Wacht war der Meinung, dass die Erfüllung der Forderungen der nationalen Autonomie der Slowenen die Anerkennung des Trialismus bedeutete, was mit den Plänen der Entente übereinstimmte. Somit habe sich der innere mit dem äußeren Feind verbunden. Dasselbe, meinten sie, passierte zu der Zeit auch bei anderen slawischen Völkern, wie den Polen oder Tschechen.

1 „Eine südslawische Kundgebung”, Deutsche Wacht, 30. Mai 1917, Nr. 43, 1; „Otvoritev avstrijskega državnega zbora”, Straža, 1. Juni 1917, Nr. 43, 2. 
/.../ durch die slawische Natur reist ein Zug der Zerstörung, /.../ der den Tschechen und Südslawen eine Inspiration zum zivilen Ungehorsam gibt, / . ./ der zum Weltkrieg führte und Korošec und Frant zu den Herolden der Entente in der österreichischen Abgeordnetenkammer machte. ${ }^{2}$

Die slowenische Bevölkerung reagierte mit großer Begeisterung auf die Mai-Deklaration. Sie äußerte sich in der sogenannten Deklarationsbewegung, in der man Unterschriften zu sammeln begann, um die Umsetzung der Deklaration zu bewirken (Stavbar 2017). Die Bewegung erreichte Zehntausende und bekam unter den Mariborer Deutschen die Überschrift Los-von-Österreich-Bewegung. Da die Regierung immer noch passiv war, nahmen die Deutschsprachigen in der Untersteiermark die Initiative in ihre eigenen Hände. Sie fingen an, sich in Volksräten zu organisieren, deren Ziel es war, einen „Ausverkauf“ der deutsch-untersteirischen Interessen zu unterbinden. Die Koordination lag in den Händen einer Bewegung, die sich Südmark nannte. Im August 1917 äußerten sich der Mariborer Bürgermeister Dr. Johann Schmiderer und der Vertreter der Deutschen aus Celje Dr. Otto Ambrožič in einem Brief an den in Wien ansässigen Deutschen Klub besorgt über die damalige politische Entwicklung und die Bemühungen der österreichischen Slawen um nationale Emanzipation. ${ }^{3}$

/.../ Die Forderung nach Errichtung eines autonomen Staatsgebietes von Slowenen, Kroaten und Serben oder die mögliche Vereinigung Sloweniens zu einer besonderen nationalen Einheit jenseits der historischen Grenzen österreichischer Kronländer ist für die Deutschen im Süden Österreichs völlig inakzeptabel /.../ und wir werden sie mit allen verfügbaren Mitteln verhindern. /.../ Diese Anforderungen sollen die Integrität des Landes Steiermark zerstören und würden nicht nur die Zerstörung des Deutschtums im Süden Österreichs bedeuten, sondern würden dem Land auch den Zugang zur Adria sowie den Handel auf dem Balkan und im Nahen Osten verhindern. ${ }^{4}$

Schmiderer und Ambrožič gaben an, dass die Erfüllung der slowenischen Forderungen die Situation der Deutschen in den Sprachinseln beeinträchtigen würde. Sie forderten daher, dass ihre Anliegen und Anfragen mit Priorität behandelt würden. Der Deutsche Klub nahm das Schreiben der beiden untersteirischen Politiker offenbar ernst.

2 „Der babylonische Turm”, Deutsche Wacht, 9. Juni 1917, Nr. 46, 1.

3 „Eine Kundgebung des deutschen Volksrates für Untersteiermark”, Deutsche Wacht, 25. August 1917, Nr. 65, 1; „Wohin steuern wir?”, Deutsche Wacht, 25. August 1917, Nr. 65, 1; „Deutscher Volksbund für Untersteiermark”, Deutsche Wacht, 25. August 1917, Nr. 65, 2; „Errichtung eines südslawischen Volksausschusses”, Deutsche Wacht, 25. August 1917, Nr. 65, 3; „Ein Autonomieministerium”, Deutsche Wacht, 1. September 1917, Nr. 66, 1; „Die Marburger Unterschriftensammlung der Los von Österreich”, Marburger Zeitung, 18. Januar 1918, Nr. 15, 3.

4 „Eine Kundgebung des deutschen Volksrates für Untersteiermark”, Deutsche Wacht, 25. August 1917, Nr. 65, 1; „Errichtung eines südslawischen Volksausschusses”, Deutsche Wacht, 25. August 1917, Nr. 65, 3; „Ein Autonomieministerium”, Deutsche Wacht, 1. September 1917, Nr. 66, 1; „,Die Marburger Unterschriftensammlung der Los von Österreich”, Marburger Zeitung, 18. Januar 1918, Nr. 15, 3. 
Am 2. September 1917 trafen sich nämlich in Maribor Vertreter deutscher Volksräte aus der Steiermark, Kärnten, Krain und dem Küstenland. Unter der Präsidentschaft von Dr. Otto Ambrožič sprachen sie sich für ein gemeinsames Auftreten gegen die Deklarationsbewegung aus. Mit Hilfe der Südmark sollte das weitere Anwachsen der Deklarationsbewegung eingedämmt werden, außerdem sprachen sie sich für eine eigene Unterschriftensammlung aus, in der sie sich gegen die Abspaltung von der Monarchie oder wie es ausdrückten, von Kaiser und Reich wandten. ${ }^{5}$

Der Gemeinderat der Stadt Maribor verfasste eine „Entschließung“ in der nicht nur die Mai-Deklaration angriffen wurde, sondern sie auch ihre Sorge um die Zukunft Österreichs zum Ausdruck brachten. Der Gemeinderat von Maribor meinte, dass es Zeit wäre, dass die Regierung aufwachen würde und mit ihrer Passivität aufhöre. ${ }^{6}$

\begin{abstract}
Die Südslawische Mai-Deklaration und die mit ihr verbundene gegenwärtig im steirischen Unterlande und im ganzen Süden Österreichs betriebene, leidenschaftliche und vor keinem mittel der Lüge und des Truges zurücksteckende Agitation und Unterschriftensammlung bezwecken die Loßreisung des gesamten südlichen Teiles der Monarchie /.../

/.../ Der Gemeinderat der Stadt Marburg erhebt gegen die deutsch- und staatsfeindlichen Pläne, sowie dagegen, dass die Regierung diesem Treiben tatenlos zusieht, nachdrückliche Verwehrung und macht die Staatsregierung schon heute für alle Folgen verantwortlich, welche aus dieser deutsch- und staatsfeindlichen Hetze entstehen. ${ }^{8}$
\end{abstract}

Doch waren die Bemühungen der untersteirischen und Mariborer deutschsprachigen Bevölkerung zu spät. Anfang des Jahres 1918 stellte der amerikanische Präsident Woodrow Wilson im Kongress sein 14-Punkte-Programm vor, in dem er sich unter anderem auch für die Selbstbestimmung der Völker der österreichisch-ungarischen Monarchie aussprach. Für die Slowenen bedeutete dieser Wandel eine neue Richtung in der Autonomiefrage; jeglicher Kompromiss oder eine Etappenlösung wurde kategorisch abgelehnt. Es ging ihnen nunmehr um eine möglichst schnelle Verwirklichung des unabhängigen südslawischen Staates (Schwabe 1971: 15-80; Klemenčič 2010: 13, 40; Lynch 2002: 419-436; Lipušček 2003). Mitte August 1918 kam es in Ljubljana zur

5 „Errichtung eines südslawischen Volksausschusses”, Deutsche Wacht, 25. August 1917, Nr. 65, 3; „Ein Autonomieministerium”, Deutsche Wacht, 1. September 1917, Nr. 66, 1; „Eine bedeutungsvolle Tagung der deutschen Volksräte von Südösterreich”, Deutsche Wacht, 7. September 1917, Nr. 67, 1.

6 PAM, Bestand Mestna občina Maribor, AŠ 49 - Ovoj Sejni spisi 1918, Sitzung des Stadtrates, 30. Januar 1918, Z1 34; PAM, Bestand Mestna občina Maribor, AŠ 49 - Ovoj Sejni spisi 1918, Geheime Sitzung des Stadtrates, 30. Januar 1918, Z1 34.

7 PAM, Bestand Mestna občina Maribor, AŠ 49 - Ovoj Sejni spisi 1918, Geheime Sitzung des Stadtrates, 30. Januar 1918, Z1 34; PAM, Bestand Mestna občina Maribor, Selecta - Ovoj 1 Predprevratna doba, Entschließung!, 31. Januar 1918, 35pr/1918.

8 PAM, Bestand Mestna občina Maribor, AŠ 49 - Ovoj Sejni spisi 1918, Geheime Sitzung des Stadtrates, 30. Januar 1918, Z1 34; PAM, Bestand Mestna občina Maribor, Selecta - Ovoj 1 Predprevratna doba, Entschließung!, 31. Januar 1918, 35pr/1918. 
einer historischen Tagung, auf der die Slowenen unter Leitung von Dr. Anton Korošec den Nationalrat für slowenische Länder und Istrien formten; dem folgten lokale Nationalräte, die die Aufgabe hatten, die Länder und die Bevölkerung auf den Umbruch vorzubereiten (Jerič 1928: 144-159; Gačič und Jenuš 2016: 50-55). ${ }^{9}$ In Maribor endstand der Nationalrat für die Steiermark am 28. September 1918, einen Monat vor dem Umbruch. Er stand unter der Leitung von Dr. Karel Verstovšek. ${ }^{10}$

Die Slowenen hatten die Gunst der Stunde genutzt und verfolgten das gleiche Ziel. Das kann man für die Mariborer und untersteirischen Deutschen nicht sagen. Bis Ende 1917 hatten es Ortsgruppen der Südmark geschafft, mehrere deutsche Volksräte in der Untersteiermark zu formen. Es gab aber in der Politik der deutschsprachigen Bewohner keine einheitliche Meinung darüber, wie man gegen die slowenischen Anforderungen und Agitationen vorgehen sollte. Im Sommer 1918 hat sich zum Beispiel die Sozialdemokratie gegen das Vorgehen der Volksräte ausgesprochen, da sie der Meinung war, ihre widersprüchliche Politik könnte langfristig dem Staat schaden und den Krieg wegen immer neuer Spannungen nur noch verlängern.

\section{DER UMBRUCH}

Bild 1: Die alte und neue Reichsbrücke in Maribor (Marburg an der Drau).

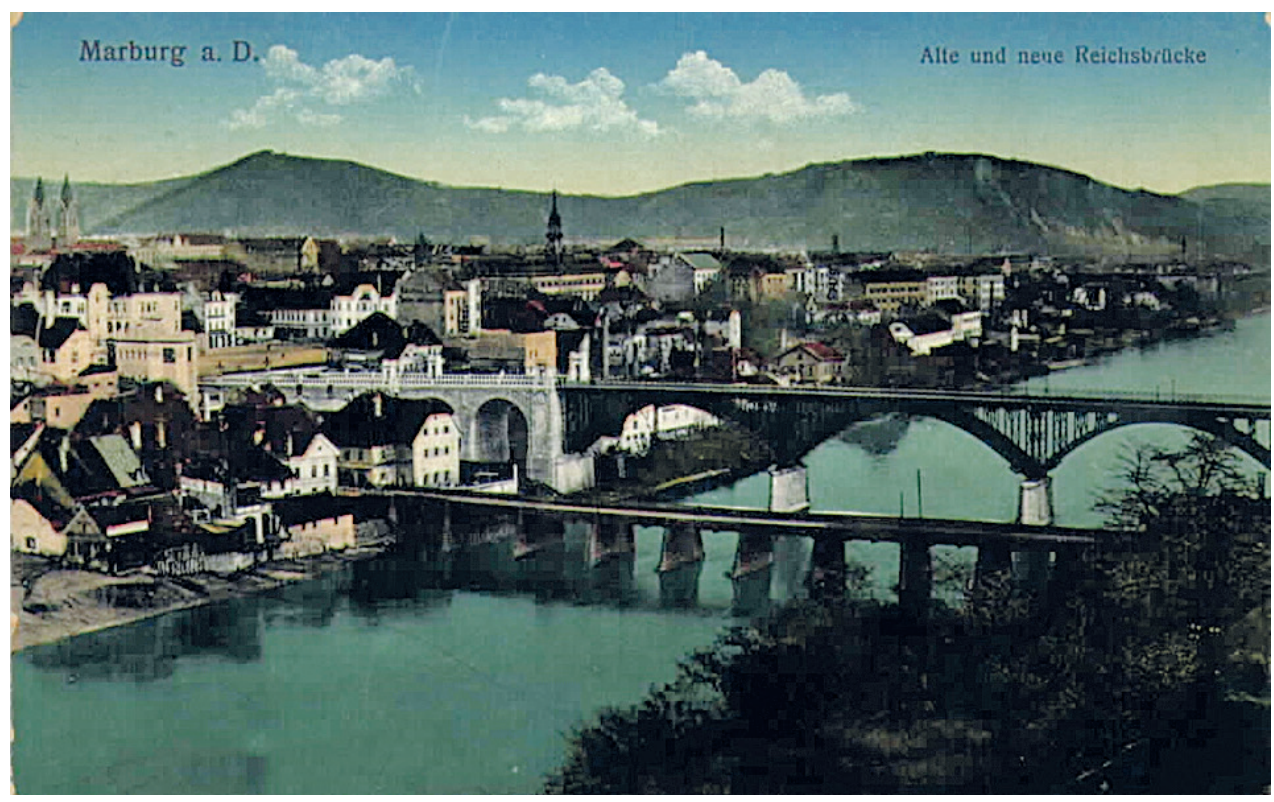

(Quelle: PAM, Sammlung von Postkarten und Bildern)

9 „Narodni svet”, Straža, 12. August 1918, Nr. 64, 1; „Ein südslawischer Kriegsrat und sein Program”, Deutsche Wacht, 16. Oktober 1918, Nr. 33, 1; „Narodni svet - Slavje v Ljubljani”, Straža, 23. August 1918, Nr. 67, 1-2.

10 PAM, Bestand Narodni svet za Štajersko, Protokoll der Gründungssitzung des Nationalrats für die Steiermark, 26. September 1918, 1. 
Am 29. Oktober 1918 kam es mit Manifestationen in Ljubljana zur Ausrufung des Unabhängigen Staates der Slowenen, Kroaten und Serben. Damit hatte das Warten der Deutschen in der Untersteirmark ein Ende. Die Slowenen machten den ersten Schritt. Am Tag darauf erließ der Mariborer Stadtrat unter der Führung von Dr. Johann Schmiderer eine Entschließung (Jenuš 2017: 920):

Die Stadt Maribor liegt auf uraltem deutschen Siedlungsgebiete, besitzt seit dem Jahre 1243 das deutsche Stadtrecht, welches sie seit dieser Zeit ununterbrochen ausübt; ihre Bewohner gehören bis auf eine kleine slowenische Minderheit dem deutschen Volke an und stehen mit dem nahegelegenen geschlossenen deutschen Sprachgebiet im Zusammenhang und in engster Wechselbeziehung.

Die freigewählte Gemeindevertretung der deutschen Stadt Marburg erklärt daher, dass aufgrund des vom Präsidenten Wilson festgelegten Selbstbestimmungsrecht die Stadt Marburg samt ihrer deutschen und wirtschaftlich zugehörigen Umgebung ein Bestandteil des neugeschaffenen deutschösterreichischen Staates ist. Den slowenischen Mitbürgern wird im Sinne der Erklärung des Präsidenten Wilson nach dem Grundsatze der Gegenseitigkeit die freieste Betätigung ihrer wirtschaftlichen und nationalen Belange gewährleistet. ${ }^{11}$

Diese Entschließung bedeutete, dass zwei neugegründete Staaten die Herrschaft über die Steiermark ausriefen. Trotz der Tatsache, dass die endgültige Grenze auf der Friedenskonferenz in Paris bestimmt werden würde, hatte dies zur Folge, dass es zwischen Deutschen und Slowenen zu noch größeren Konflikten kommen würde (Gačič und Jenuš 2016: 97).

Am 1. November 1918 widersetzte sich Rudolf Maister, Kommandant des Landsturm-Bezirkskommandos 26, dem Stationskommandanten Anton Holik und verweigerte den Gehorsam. Mit nur wenigen Einheiten übernahm er die Kontrolle über die Stadt Maribor. Er erklärte Maribor zum jugoslawischen Staatsgebiet und wurde noch am selben Tag im Mariborer Narodni dom (Volksheim) zum General ernannt (Gačič und Jenuš 2016: 98-99; Jenuš 2013: 224; Hartman 1989: 94-95, 117; Hartman 1998: 41; Ude 1979: 374; Potočnik 2008: 62).

Maister verstand es gut, die Situation zu nutzen. Die Steiermark versank im Chaos. Die Obersteiermark mit Graz hatte Probleme, ihre Ernährung und Heizung zu sichern und war im großen Masse von Lieferungen aus dem neuen südslawischen Staat abhängig. Die politischen Führungen der untersteirischen Städte und Märkte konnten sich nicht einigen, wer die politische Macht in den Händen hält; all das nutzte Maister aus. Maisters Truppen besetzten alle umliegenden Orte von Maribor und drangen teilweise über die deutsch-slowenische Sprachgrenze nach Norden (nach Radkersburg, Spielfeld, Mureck, Abstall usw.) vor (Jenuš 2013: 224-225).

11 PAM, Bestand Mestna občina Maribor, AŠ 49 - Ovoj Sejni spisi 1918, Sitzung des Stadtrates, 30. Oktober 1918, Proklamation des Stadtrates von Maribor; PAM, Bestand Mestna občina Maribor, Selecta - Ovoj 1 - Predprevratna doba, Entschließung, s. d.,12pr/1918. 
In Maribor war die Lage am angespanntesten. Zum Schutz des deutschen Eigentumes hatte der Stadtrat am 3. November die Anordnung zur Formierung von Volkswehreinheiten gegeben - der sogenannten „Grünen Garde“ oder „Marburger Schutzwehr“. Diese wuchsen im Laufe des Monats November auf fast 1.000 Mann an. Deswegen endschied sich Maister zum Handeln und zwang die Truppen der deutschen Schutzwehr in einer „Nacht und Nebel Aktion“ am 23. November 1918 zu Kapitulation (Jenuš 2018). ${ }^{12}$ Trotz Protesten der neuen Grazer Landesregierung war Maister erneut erfolgreich. Auch in den folgenden Wochen kam es immer wieder zu Zusammenstößen zwischen slowenischen und deutsch-österreichischen Truppen. Auf den steirischen Grenzgebieten zwischen dem am 1. Dezember 1918 entstandenen Königreich der Serben, Kroaten und Slowenen und Deutsch-Österreich bemühten sich beide Länder, diese Geschehnisse als unangenehme Grenzzwischenfälle darzustellen. Nicht zuletzt, da beide Länder am 12. Dezember 1918 ein Abkommen unterzeichneten, dass die endgültige Grenzfrage auf der zukünftigen Friedenskonferenz geregelt werden würde (Jenuš 2013: 233).

Nach zwei Monaten von Ungewissheit, wer die politische Macht in der Stadt Maribor in seinen Händen hielt, hatten die Slowenen Anfang 1919 diese auch übernommen; bis dahin funktionierte nämlich der deutsche Mariborer Stadtrat ohne größere Einschränkungen. Am 2. Januar 1919 übergab der letzte Mariborer Bürgermeister der österreichischen Ära, Dr. Johann Schmiderer, in Anwesenheit Maisters dem slowenischen politischen Kommissar, Dr. Vilko Pfeifer, den Stadtrat. Um Ordnung unter der deutschen Bevölkerung zu gewährleisten, endschied sich Maister, 21 namhafte deutsche Industrielle und Politiker als Geiseln zu nehmen. Maisters Vorschläge stießen auf Empörung, sowohl auf Seiten der Würdenträger in Ljubljana als auch in Graz und Wien (Žerjav 1918: 3-15; Maister 1934: 228; Jenuš 2011a: 161, 242). ${ }^{13}$

Der Zeitpunkt für solche Unterfangen war nämlich schlecht gewählt. Im Januar 1919 war in der Steiermark die sogenannte US-Coolidge Kommission präsent, um sich ein Bild von der ethnischen Situation in Marburg und seiner Umgebung zu machen. Unter der Führung von Oberstleutnant Sherman Miles sammelte die Kommission Informationen, die den Expertengruppen in Paris helfen sollten, die zukünftige jugoslawisch-österreichische Grenze in der Steiermark zu ziehen. Für den 27. Januar kündigte sich die Kommission in Maribor an. General Maister empfing die US-amerikanische Delegation. Ein Teil der deutschen Bevölkerung Marburgs und der Umgebung versammelte sich vor dem Rathaus und drückte durch ihre österreichischen und deutschen Fahnen ihren Willen aus, bei Österreich bleiben zu wollen. Die Kundgebung soll 10.000 Demonstranten versammelt haben - darunter auch Gymnasiasten und Realschüler, die von ihren deutschen Lehrern auf den Marburger Hauptplatz geführt wurden (Senekonič 1936: 59-64 und 110-114; Karner 2000: 59-60; Rahten 2020: 159-180).

12 ARS, Bestand Ude Lojze, AŠ 20; ARS, Bestand Pokrajinska uprava za Slovenijo, Predsedstvo, AŠ 9, Materialien für die 26. Sitzung.

13 PAM, Bestand Mestna občina Maribor, AŠ 49 - Ovoj Sejni spisi 1918, Protokoll der Übernahme der Gemeindeverwaltung, 2. Januar1919, 1; „Zgodovinski dan v Mariboru”, Straža, 3. Januar 1919, Nr. 1, 2; „Mariborska mestna občina v slovenskih rokah”, Nova doba, 8. Januar 1919, Nr. 2, 2. 
Die Lage war unübersichtlich. In dem Gedrängel kam es zwischen den slowenischen Schutztruppen und den Demonstranten zu Streitigkeiten. 47 Schüsse fielen. Die traurigen Folgen waren 7 Tote, 60 Verletzte - darunter 4 Schüler (Senekonič 1936: 63). ${ }^{14}$

Die Geschehnisse dieses Tages gingen als Mariborer Blutmontag in die Geschichte ein. Beide Seiten nutzten dies für ihre Propaganda. Der steirische Landeshauptmann Wilhelm Kaan protestierte bei der Wiener Regierung und erwog sogar ein militärisches Eingreifen. Die Slowenen hingegen waren empört, dass deutsche Lehrer ihre Schüler zu den Demonstrationen hetzten. Dies hatte zur Folge, dass die deutsche Lehrerschaft - insgesamt 36 Gymnasial- und 300 Volksschullehrer - in den nächsten Wochen ihre Arbeit verloren (Senekonič 1936: 59-64 und 110-114; Jenuš 2011a: 137-159; Karner 2000: 59-60; Rahten 2020: 159-180).

\section{EIN EIGENSTÄNDIGER SÜDSLAWISCHER STAAT UND DIE FRAGE DER UNTERSTEIRISCHEN DEUTSCHEN}

Im Frühjahr 1919 wurde die Lösung der steirischen Frage den Diplomaten in Paris überlassen. Expertenberichte mit Angaben zur historischen, wirtschaftlichen, kulturellen Entwicklung der Steiermark wurden vorgelegt. Die steirische Denkschrift wurde von den Experten Robert Sieger und Franz Kamniker verfasst, die untersteirische von Dr. Franc Kovačič. Beide Seiten bemühten sich, ihre Sicht der Dinge vorzustellen, doch in Wahrheit galten in Paris andere Regeln. Die Alliierten verfolgten ihre Interessen - im Sommer 1919 entwickelte sich ein Hin und Her. Der Mariborer Blutmontag sowie die österreichischen Volkszählungen, die für die Slowenen ein schlechter Ausgangspunkt waren, standen zur Debatte. Wegen des ethnisch stark gemischten Gebietes schlug die deutschösterreichische Delegation, unterstützt von den Italienern, eine Volksabstimmung in der Untersteiermark vor, was aber zum Glück für die Slowenen von den Franzosen und Briten abgelehnt wurde (Karner 2000: 60-62; Jenuš 2011b: 177-194).

Letzten Endes endschied man, die von Maister besetzten Gebiete in der Steiermark würden den Slowenen zugesprochen. Spielfeld blieb in den Händen der Deutsch-Österreicher, Radkersburg wurde geteilt. Der österreichische Friedensvertrag wurde am 10. September 1919 unterschrieben. Mit dem in Saint-Germain unterzeichneten Vertrag garantierte das Königreich der Serben, Kroaten und Slowenen der deutschen Minderheit im neuen jugoslawischen Staat einen minimalen Minderheitenschutz (Karner 2000: 60-62; Jenuš 2011b: 177-194). Nach Artikel 51 des Vertrags verpflichtete sich das Königreich SHS, die Interessen der nationalen, sprachlichen und religiösen Minderheiten zu schützen (Benedik 2002: 249-253).

14 „Krvavi izgredi”, Mariborski delavec, 28. Januar 1919, Nr. 22, 1; „Ponedeljkovi izgredi v Mariboru”, Slovenski gospodar, 30. Januar 1919, Nr. 5, 1; „Nemški izgredi v Mariboru”, Slovenski gospodar, 30. Januar 1919, Nr. 5, 1; „Krvavi spopadi v Mariboru”, Slovenec, 28. Januar 1919, Nr. 22, 1; „Na zvoniku stolne cerkve”, Nova doba, 1. Februar 1919, Nr. 9, 1; ,Schwere Ausschreitungen jugoslawischer Truppen in Marburg”, Die Neue Zeitung, 29. Januar 1919, Nr. 28, 1-2; „Blutbad in Marburg”, Pester Lloyd, 29. Januar 1919, Nr. 25, 4; „Das Blutbad in Marburg”, Wiener Allgemeine Zeitung, 28. Januar 1919, Nr. 12230, 4; „Die blutigen Vorfälle in Marburg”, Reichspost, 29. Januar 1919, Nr. 47. 
Der serbisch-kroatisch-slowenische Staat ist damit einverstanden, dass die alliierten und assoziierten Hauptmächte in einem mit ihm zu schließenden Vertrage die Bestimmungen aufnehmen, die sie zum Schutze der Interessen der nationalen, sprachlichen und religiösen Minderheiten im serbisch-kroatisch-slowenischen Staate für notwendig erachten und genehmigt damit diese Bestimmungen (Benedik 2002: 253).

Der jugoslawische Staat verpflichtete sich, den Minderheiten den freien Gebrauch ihrer Sprache im öffentlichen Leben zu ermöglichen, außerdem das öffentliche Minderheitenschulwesen in der Sprache der Minderheit dort zu regeln, wo eine ausreichende Anzahl von Angehörigen der Minderheit lebte (Benedik 2002: 254). Auf dem Papier schien das zwar eine gute Regelung zu sein, leider aber war die Umsetzung dessen ungenügend.

Mit dem Zerfall der österreichisch-ungarischen Monarchie wurden die Deutschen im neuen jugoslawischen Staat zu einer nationalen Minderheit, die sich nur schwer mit der neuen Situation abfand (Winkler 1931: 206; Biber 1961: 11; Ferenc und Repe 2004: 148; Wehler 1980: 16-17). Nach der österreichischen Volkszählung im Jahr 1910 lebten in den slowenischen Gebieten, die nach den Pariser Friedensverträgen an den jugoslawischen Staat fielen, rund 106.377 Personen mit deutscher Umgangssprache. Ein Großteil davon lebte im Gebiet der Untersteiermark - etwa 69 \%. Die Deutschen lebten in der Steiermark vor allem in urbanen Siedlungen - Städten und Märkten, insbesondere in drei sogenannten urdeutschen Städten Maribor (Marburg), Celje (Cilli) und Ptuj (Pettau). In diesen Städten waren die Deutschen bis zum Zerfall der Doppelmonarchie die Träger des politischen, wirtschaftlichen und kulturellen Lebens.

Tabele 1: Die Ergebnisse der Volkszählung in der Untersteiermark und Maribor (Marburg) in den Jahren 1910, 1921, 1931. ${ }^{15}$

\begin{tabular}{|c|c|c|c|c|c|c|c|}
\hline \multirow{3}{*}{$\begin{array}{l}\text { Untersteier- } \\
\text { mark }\end{array}$} & \multirow{3}{*}{$\begin{array}{l}\sum^{*} \\
\text { Deutsche } \\
\end{array}$} & \multirow{2}{*}{\multicolumn{2}{|c|}{\begin{tabular}{|l|}
1910 \\
486.568 \\
\end{tabular}}} & \multirow{2}{*}{\multicolumn{2}{|c|}{\begin{tabular}{|l|}
1921 \\
496.103 \\
\end{tabular}}} & \multirow{2}{*}{\multicolumn{2}{|c|}{$\begin{array}{l}1931 \\
541.036 \\
\end{array}$}} \\
\hline & & & & & & & \\
\hline & & 73.148 & 15,03 & 22.531 & 4,54 & 12.410 & 2,29 \\
\hline & Slowenen & 403.981 & 84,97 & 436.740 & 88,03 & 512.392 & 94,7 \\
\hline & Andere | & 0 & 0 & 36.832 & 7,43 & 16.234 & 3,01 \\
\hline \multirow{4}{*}{$\begin{array}{l}\text { Maribor } \\
\text { (Marburg an } \\
\text { der Drau) }\end{array}$} & $\sum *$ & \multicolumn{2}{|l|}{27.994} & \multicolumn{2}{|l|}{30.662} & \multicolumn{2}{|l|}{33.131} \\
\hline & Deutsche & 22.653 & 80,90 & 6.595 & 21,5 & 2.741 & 8,27 \\
\hline & Slowenen & 3.823 & 13,65 & 20.759 & 67,7 & 27.994 & 84,49 \\
\hline & Andere & 1.518 & 5,45 & 3.308 & 10,8 & 2396 & 7,24 \\
\hline
\end{tabular}

15 S. Karner (1998: 26); Komac (2007: 512); Klemenčič (1994: 53-54); Klemenčič (1986: 465-470); Cvirn (1998: 36-37); Čuček (2006: 387). 
Im Jahr 1910 lebten in Maribor 22.653 Einwohner, die der Volkszählung nach die deutsche Sprache als Umgangssprache anführten. Das war mehr als 80 Prozent der Gesamtbevölkerung der Stadt. Die Slowenen bildeten in der (heute slowenischen) Stadt mit 3.823 Bewohnern bzw. 13,65 Prozent eine Minderheit. Wenn wir uns die Informationen für die Mariborer Umgebung (den politischen Bezirk Maribor) oder die Untersteiermark ansehen, sehen wir, dass das Verhältnis umgekehrt war. Maribor war eine deutsche Sprachinsel, umgeben von einer mehr oder weniger geschlossenen slowenischen ruralen Umgebung. In den beiden jugoslawischen Volkszählungen vor dem Zweiten Weltkrieg, in den Jahren 1921 und 1931, ging die Zahl der Einwohner, die sich als Deutsch bezeichneten, dramatisch zurück. Im Jahr 1921 lebten nur noch 6.598 Personen oder 21 Prozent der Bevölkerung, die Deutsch als ihre Muttersprache angaben, in Maribor, und im Jahr 1931 gar nur noch 2.741 oder 8 Prozent. Die Unterschiede in den Resultaten der beiden Volkszählungen haben mehrere Gründe. Der eine könnte in der sogenannten „statistischen Assimilierung“ liegen. Das österreichische System befragte die Bewohner nach der Umgangssprache, die in den steirischen wirtschaftlichen und bürokratischen Schaltstellen natürlich Deutsch war, wo hingegen die jugoslawische Volkszählung nach der Muttersprache fragte. Ein Teil der „verlorenen“ Bevölkerung können somit Slowenen gewesen sein, die sich in der Vergangenheit als Deutsche ausgaben; doch der Verlust von mehr als 50 Prozent der Stadtbevölkerung hat tiefliegende Gründe (Klemenčič 1994: 53-54; Jenuš 2011; Jenuš 2014: 40).

Mit dem Umbruch begannen die Slowenen in der Untersteiermark (bzw. im gesamten von Slowenen kontrollierten Gebiet) Reformen einzuführen, die man als „Entaustrifizierung" bezeichnen kann: die Einführung der slowenischen Sprache als Amtssprache, die Slowenisierung des Schulwesens, Einschnitte im kulturellen und wirtschaftlichen Leben. In Maribor und seiner Umgebung bedeutete die Einführung der slowenischen Reformen eine große Hürde, vor allem in der Verwaltung, wo Beamte, die der slowenischen Sprache nicht mächtig waren, entlassen wurden. Sie blieben praktisch über Nacht ohne Verdienstmöglichkeiten und waren dazu gezwungen, über die Grenze nach Österreich auszuwandern. Schon Ende 1918 entließ die neue slowenische Obrigkeit mehrere hundert Beamte, Postarbeiter und Eisenbahner; im Frühjahr 1919 folgten nach dem Blutmontag Lehrer, die aufgrund des Vorwurfs der Staatsfeindlichkeit entlassen wurden. Die deutschsprachigen Flüchtlinge gingen über die Grenze nach Deutschösterreich, wo sie bei der Grazer Landesregierung um Hilfe baten. Insgesamt kamen in dieser ersten Welle fast 500 Familien (ungefähr 2.000 Personen) an. Die Grazer Landesregierung brachte sie in Graz (270 Familien), Bruck an der Mur (72 Familien), Leibnitz (49 Familien), Leoben und anderen Orten in der Steiermark unter (Dolenc 2004: 81-82; Jenuš 2014: 40). ${ }^{16}$

In der Zwischenkriegszeit, vor allem in den zwanziger Jahren, hat die deutschsprachige Kultur große Veränderungen erfahren. Weil sehr viele deutsche Kulturorganisationen vor dem Ersten Weltkrieg eine starke politische und nationale Note hatten, galten sie nach dem Umbruch bei den Slowenen nicht mehr viel. Sie wurden als ein Mittel

16 „So-li Nemci narodna manjšina ?” Jutro, 10. März 1922, Nr. 59, 2. 
angesehen, den deutschsprachigen Einfluss auszuweiten und die Germanisierung der slowenischen Bevölkerung anzustreben. Mit Abstand die wichtigsten deutschen Kulturorganisationen vor dem Ersten Weltkrieg waren der Schutzverein Südmark und der Deutsche Schulverein. Dem ersten warf man vor, dass er durch gezielte Ansiedelung deutschsprachiger Familien in gemischtsprachigen slowenischen ruralen Gebieten die nationale Struktur des Landes verändere und die Entstehung eines geschlossenen deutschsprachigen Raums in der Untersteiermark anstrebte; dem zweiten, das er durch das deutsche Schulwesen versuche, die Germanisierung slowenischer Kinder zu erreichen (Potočnik 2003: 143-153; Jenuš 2014: 40).

Diese beiden deutschen Organisationen wurden durch einen Erlass der slowenischen Landesregierung verboten. Als Grund wurde nicht ihr Ruf angegeben, sondern die Tatsache, dass sie ihren Sitz im Ausland hatten - in Graz und Wien. ${ }^{17}$

Dennoch gelang es den Deutschen, zumindest einen Teil ihrer Vorkriegskultur zu bewahren. In den zwanziger und dreißiger Jahren waren in Maribor und Umgebung zahlreiche deutsche Vereine aktiv, wie der Liederbund der Bäcker, Marburg and der Drau, Fahradklub Edelweiss, Verein der deutschen Bautechniker in Maribor, Der landwirtschaftliche Leseverein in Rosswein oder der Sportverein Rapid. Wegen des ständigen Drucks der slowenischen Behörden sowie der Emigration ihrer Mitglieder kam es zwar schrittweise zum Verfall vieler Vereine. Trotzdem aber haben einige, wie der Sportverein Rapid oder der Fahradklub Edelweiss überlebt (Baš 1989: 274; Ratej 2006: 450; Jenuš 2014: 40-41). ${ }^{18}$

Die wichtigsten deutschen Vereine in den Zwischenkriegsjahren waren der Marburger Männergesangsverein und der im Jahr 1922 gegründete Verein Politischer und wirtschaftlicher Verein der Deutschen in Slowenien, der seinen Sitz in Maribor hatte und unter der Leitung von Dr. Lothar Mühleisen stand. Der Verein vereinte namhafte Vertreter der deutschen Minderheit in der Steiermark - Karl Nasko, den ehemaligen Vizebürgermeister aus Maribor, Viktor Spruschnig aus Ptuj, Hans Schmiderer (Sohn des ehemaligen Bürgermeisters) (Jenuš 2014: 41; Cvirn 1989: 86-88). Auf der Liste des Politischen Vereines gelang es Lothar Mühleisen, in den Mariborer Stadtrat gewählt zu werden; 1927 sogar in die jugoslawische Nationalversammlung in Belgrad.

Der Verein sprach sich für die Sicherung des deutschen Gewerbes und des Eigentumes in Slowenien aus. Obwohl die Mariborer Deutschen auch in den zwischen Kriegsjahren noch die größte wirtschaftliche Kraft in der Untersteiermark waren, waren sie besorgt darüber, dass die Verstaatlichung ihres Eigentumes, Gewerbes oder ihrer Betriebe, der sie bis 1924 Zeuge waren, erneut durchgeführt werden könnte. 1919 hatte der neue jugoslawische Staat alle Unternehmen, Gebäude und Grundstücke, die im Besitz von denjenigen Ausländern waren, die man als staatsfeindlich ansah, unter staatliche Kontrolle (Sequester) gestellt. Im Fall von Maribor traf die Verstaatlichung 31 Unternehmen.

17 Uradni list Deželne vlade za Slovenijo, 5. Juni 1919, Nr. 52, 351, 352.

18 PAM, Bestand Mestna občina Maribor, AŠ 162 - Ovoj Sejni spisi 1925, Stadtratssitzung MOM, 7. April 1925, 10-11; „Ustanovitev nemške stranke v Mariboru”, Tabor, 29. Oktober 1922, 2; „Nemška nevarnost”, Slovenski narod, 13. Mai 1923, 1; „Nemci in minister dr. Zupanič”, Slovenski narod, 13. Mai 1923, 1. 
Die Verstaatlichung wurde erst 1924 aufgehoben, nachdem es zu einem Abkommen mit der Republik Österreich kam (Oset 2010: 79, 121-124; Ogrizek 2006). ${ }^{19}$

Wenn wir aber die vorübergehende Verstaatlichung der deutschen Besitztümer außer Acht lassen, war die wirtschaftliche Lage der deutschen Minderheit in der Untersteiermark im Vergleich zu den anderen Deutschen im jugoslawischen Staat, auch der Gottscheer Deutschen, wesentlich stabiler. Sie waren sowohl Großgrundbesitzer als auch Besitzer von Immobilien und hatten einen großen Einfluss auf das Leben der slowenischen Bevölkerung, die immer noch zu großen Teilen von ihnen abhängig war.

\section{5 ,DIE DEUTSCHE MINDERHEIT WIRD KEINE RECHTE HABEN, WEIL ES SIE NICHT GEBEN WIRD“"}

Gerade die soziale und wirtschaftliche Abhängigkeit der Slowenen nutzte die deutsche Minderheit nach dem Aufstieg des Nationalsozialismus in Deutschland zu ihrem Gunsten. Nach dem Zweiten Weltkrieg hatte der damalige jugoslawische Geheimdienst, die sogenannte UDBA, einen Bericht über die Volksdeutschen verfasst und dem umstrittenen Verein für das Deutschtum im Auslande (VDA) eine führende Rolle bei der Nazifizierung der Deutschen in der Steiermark zugewiesen. Der VDA wurde anfangs als eine Hilfsorganisation der Deutschen im Ausland aufgebaut. Mit dem Aufstieg der NSDAP in Deutschland übernahm die VDA in der Untersteiermark eine neue Rolle. Die VDA versuchte über den sogenannten Grazer akademischen Kreis (bestehend aus Robert Seiger, Franz Wehofsich, Herman Ibler und Hellmut Carstein), auf zwei Wegen eine Revidierung der Parieser Friedensverträge zu schaffen: durch eine wissenschaftliche Forschung, die Beweisen sollte, dass die Untersteiermark zu Deutschösterreich gehöre, sowie mit der Verbindung mit dem in der Untersteiermark ansässigen deutschen Kulturbund. Dies gelang ihnen vor allem nach dem „Anschluss“ Österreichs an das Deutsche Reich (Jenuš 2016: 155-158). ${ }^{20}$

In einem Bericht des Innenministeriums kann man sehen, dass auch die jugoslawische Regierung wusste, dass es zu einer Radikalisation der Deutschen in Jugoslawien kommen könnte. Die NSDAP habe die jugoslawischen Deutschen mit Propagandamaterial versorgt.

/.../ Bücher, Zeitungen und anderen Schriften, die nationalsozialistischen Inhalt haben. Diese Texte enthalten Berichte über den schlechten Zustand der jugoslawischen Deutschen, sie propagieren eine Ideologie, die den jugoslawischen Gesetzen widerspricht und die wir deshalb abschalten müssen. ${ }^{21}$

Kurz nach dem „Anschluss“ Österreichs an das Deutsche Reich wurden Rufe nach einer Revision des unrechten Pariser Friedensvertrages laut. Der Vertrag hatte nämlich

19 Siehe auch: PAM, Bestand Okrožno sodišče Maribor, Handelsregister.

20 ARS, Bestand Republiški sekretariat za notranje zadeve SRS, AŠ 1063, Volksdeutscher - Analyse 1966, 1, 2.

21 ARS, Bestand Republiški sekretariat za notranje zadeve SRS, AŠ 1063, Volksdeutscher - Analyse $1966,1,2$. 
verursacht, dass die Steiermark ein Gebiet von fast $6.100 \mathrm{~km}^{2}$ und damit auch eine halbe Million Einwohner (Karner 1978: 51) verlor. In Maribor fand diese revisionistische Politik Anklang unter den Kulturbund-Mitgliedern, die anfingen, in der Öffentlichkeit nationalsozialistische Lieder zu singen oder Parolen zu rufen, wie: „Hitler ist unser Führer! Heil! Sieg. Die Windischen am Strick!“ oder „Wir wollen heim ins Reich!“ (Biber 1966: 143).

Lange mussten die Mitglieder des Kulturbundes nicht warten. Im April 1941 kam es zu einer überraschenden, aber schnellen Besetzung Jugoslawiens. Die slowenischen Gebiete wurden unter den Achsenmächten aufgeteilt..22 Die Steiermark wurde als Reichsgau unter der Führung Dr. Siegfried Überbreiters organisiert. In den ersten Tagen nach der Besetzung hatte die nationalsozialistische Militärbehörde keine größeren Probleme beim Vorrücken. In Maribor und seiner Umgebung halfen der deutschen Armee Mitglieder des Kulturbunds, die mit Hilfe von geheimen Radioverbindungen im ständigen Kontakt standen.

Nur einen Tag nach Beginn der Angriffe auf das Königreich Jugoslawien besuchte den stellvertretenden Bürgermeister in Maribor, Franjo Žebot, der Leiter des Kulturbundes für die Drau-Banschaft, Hans Baron, und erklärte, es sei weise für die jugoslawischen Behörden, mit den nationalsozialistischen Behörden zusammenzuarbeiten, um Verluste bei den Jugoslawen zu vermeiden. Žebot wurde gewarnt, dass er „..für jedes Opfer unter den Maribor-Deutschen verantwortlich sein wird“ und „zehn Slowenen für jeden getöteten Deutschen erschossen würden" (Čoh 2006: 499).

Nachdem sich die Lage einigermaßen beruhigt hatte, fing das NS-Regime unter der Leitung des Gauleiters Überbreiter mit der Aussiedelung von Slowenen aus der Untersteiermark, aus Oberkrain und dem Mießtal an.

\begin{abstract}
Wir wollen dieses Land so heranbinden, dass darinnen nur Platz hat der Deutsche und jene Steirer, die Jahre und Jahrzehnte und Jahrhunderte hindurch treu und kameradschaftlich Schulter an Schulter mit unseren Volksgenossen gekämpft haben, die, uns blutmäßig sehr nahe verwandt, bereit gewesen sind, auch in den letzten Jahrzehnten mit allen Fasern ihres Herzens den Anschluss an Deutschland herbeizusehen. Mit diesen wollen wir arbeiten. Und alles andere, meine Volksgenossen, daraus mache ich auch öffentlich kein Hehl, das muss hinaus. ${ }^{23}$
\end{abstract}

Die Slowenen wurden von dem SS-Rasse- und Siedlungshauptamt einer rassischen Überprüfung unterzogen und in vier Rassekategorien eingeteilt. Bei seinem Besuch in Maribor im Juni 1941 äußerte sich Heinrich Himmler, dass alle rassen-ungeeigneten Elemente aus den Besetzungsgebieten entfernt werden müssten. Himmler bestand an diesen Aussiedlungen, da er Platz für die Gottscheer Deutschen schaffen musste, denen Hitler

22 „Nemčija začela vojno z Jugoslavijo”, Slovenski gospodar, 9. April 1941, 2; „Die Machtergreifung in Marburg”, Marburger Zeitung, 9. April 1941, 1; „Die deutschen Soldaten in Marburger Stadtbild”, Marburger Zeitung, 10. April 1941, 5; „Marburg im Spiegel der jüngsten Ereignisse”, Marburger Zeitung, 11. April 1941, 5.

23 „Es spricht der Gauleiter.“ Marburger Zeitung, 15. April 1941, 1. 
versprach, sie bis zum Herbst 1941 ins Reich umzusiedeln. Nach Schätzungen soll das NS-Regime den Plan gehabt haben, rund 220.000 Menschen aus ihren Besatzungsgebieten auszusiedeln. Aus Maribor wurden im Jahr 19414.434 Menschen nach Serbien und Bosnien ausgesiedelt, 689 Menschen wurden erschossen (Ferenc 1993: 17-40).

Mit dem Andauern des Krieges verlor das NS-Regime die Kontrolle. Die Jugoslawen hingegen gewannen mit Hilfe der Alliierten nach und nach die Oberhand. Schon während des Krieges kam es zu Debatten, was mit den Deutschen nach dem Kriege geschehen sollte. Die Kriegssieger (wenn man im Krieg überhaupt von Siegern sprechen kann) entschieden, dass die Deutschen eine Kollektivschuld trügen - unabhängig davon, ob es sich um autochthone Deutsche handelte oder nicht - und sie müssten Slowenien verlassen. Die Abteilung für Volksschutz (OZNA) bekam die Aufgabe, belastende Beweise gegen die Deutschen zu sammeln und außerdem Übergangs- und Konzentrationslager zu errichten, in denen die Deutschen auf ihr Schicksaal warten sollten (Ferenc 1988: 114-116; Repe 1998: 145, 146). Maribor und seine Umgebung bekamen in dieser Auseinandersetzung eine besondere Rolle zugesprochen. In Bresternica bei Maribor, Studenci bei Maribor und Kamnica bei Maribor richtete man Lager ein, aus denen Zehntausende Deutsche in den Tod oder in eine ungewisse Zukunft gebracht wurden. Ausgehend von der Statistik der Abteilung für Volksschutz, die im Slowenischen Staatsarchiv aufbewahrt wird, wurden allein in den Jahren 1945-1946 mehr als 9.474 Deutsche ausgesiedelt. Eine Namensliste mit 5.433 Namen der Ausgesiedelten ist noch erhalten (Mikola 2007: 11; Ferenc 1998: 125; Jenuš 2016: 167-168). ${ }^{24}$

Tabelle 2: Statistiken des vertriebenen Volksdeutschen aus der Volksrepublik Slowenien.

\begin{tabular}{|l|l|}
\hline $\begin{array}{l}\text { 1945-1946 } \\
\text { Statistiken des vertriebenen Volksdeutschen } \\
\text { aus der Volksrepublik Slowenien }\end{array}$ \\
\hline Bezirk & Anzahl der Vertriebenen \\
\hline Ljubljana - Umgebung & 89 \\
\hline Ljubljana - Stadt & 447 \\
\hline Kranj & 499 \\
\hline Kamnik & 124 \\
\hline Jesenice & 350 \\
\hline Trbovlje & 83 \\
\hline Celje & 509 \\
\hline Mozirje & 125 \\
\hline Krško & 1129 \\
\hline
\end{tabular}

24 ARS, SI AS 1931, Bestand Republiški sekretariat za notranje zadeve SRS, AŠ 1062, Statistiken der Volksdeutschen Auswanderer aus der Volksrepublik Slowenien in den Jahren 1945-1946, 26.11.1951. 


\begin{tabular}{|l|l|}
\hline $\begin{array}{l}\text { 1945-1946 } \\
\text { Statistiken des vertriebenen Volksdeutschen } \\
\text { aus der Volksrepublik Slowenien }\end{array}$ \\
\hline Bezirk & Anzahl der Vertriebenen \\
\hline Novo mesto & 10 \\
\hline Čnomelj & 3 \\
\hline Kočevje & 35 \\
\hline Gorica & 3 \\
\hline Maribor - Stadt & 1662 \\
\hline Maribor - Umgebung & 791 \\
\hline Poljčane & 154 \\
\hline Ptuj & 151 \\
\hline Ljutomer & 59 \\
\hline Dravograd & 531 \\
\hline Radgona & 1344 \\
\hline Murska Sobota & 481 \\
\hline Vertriebene & $\mathbf{7 , 4 7 0}$ \\
\hline $\begin{array}{l}\text { Vertriebene } \\
\text { Volksdeutsche ohne } \\
\text { Bezirksangabe }\end{array}$ & 2004 \\
\hline Insgesamt & $\mathbf{9 . 4 7 4}$ \\
\hline
\end{tabular}

(Quelle: ARS, Bestand Republiški sekretariat za notranje zadeve SRS, AŠ 1062, Statistiken der vertriebenen Volksdeutschen aus der Volksrepublik Slowenien 1945-1946 vom 26. 11. 1951) 
Bild 2: Boris Kidrič auf der Sitzung des Hauptkomitees der Befreiungsfront Ljubljana am 15. Dezember 1945 in Ljubljana über die Frage der deutschen Minderheit.

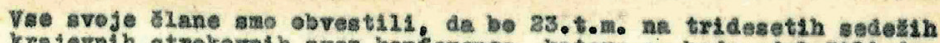
krajevnih trekrovih zves konferenos, katere se bodo udelexill de

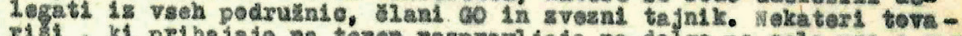
xisi. ki prihajajo na teron raspravijajo na dolgo po celo uro o vpre-

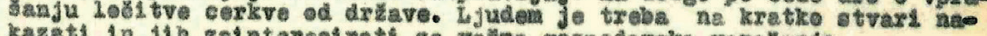
kazat1 in jih zalnteresirats za vasna gospodarsika vorasknja.

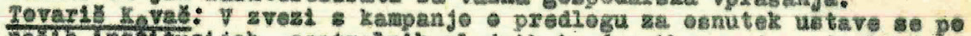
nasih instituel jah, centrahnih vladnih in drugth zunaj postavi jajo

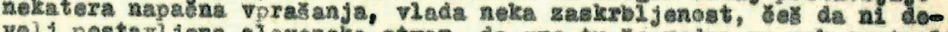
volj postavijena slovenske stvar, da gre tu se vedno ga nek centrall-

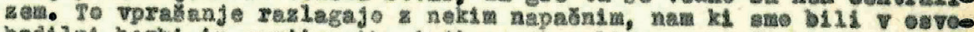

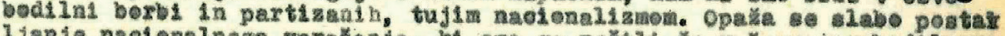

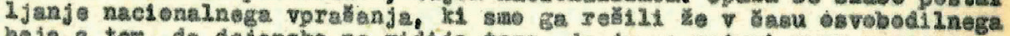
boja a tem, da dejansko ne vidijo tega, da je po us tavi man zagarant1 rana viem narodom popolna onakopravnost, da jo popolnoma reseno na-

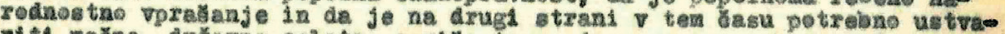

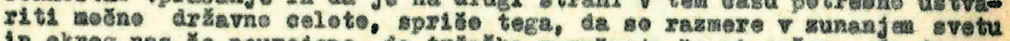

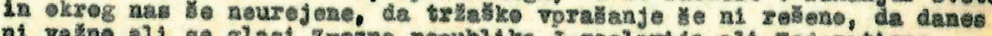

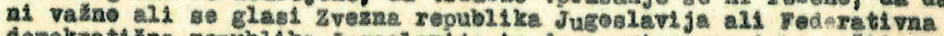

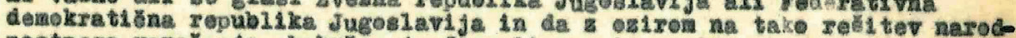

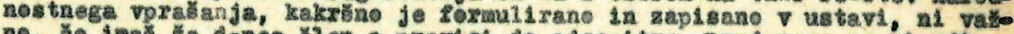

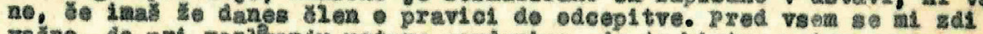
valno, da pri razlganju ustave poviarimo, de je blstvo ustave ravmo $v$ te tem, da je oblast $v$ Ijudakih fxontah in ha drug strani, kax jo posredno vprăanje, da so v zvos 1 s tem gpremenile drühene oblikg, da

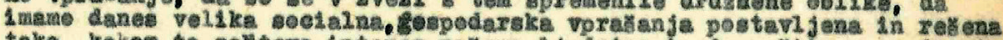
tako, kakoz to galltevs interes nag ega Ijudstva in da reatitev narodnostnega vpräanja 1zhaja 12 teh pravih dveh smell. Vakko drugadno razla-

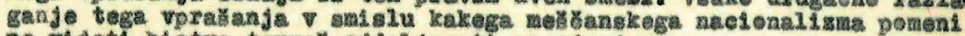
ae videti bistva temver oddaljevati se od njega.

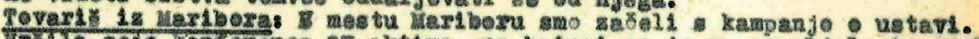

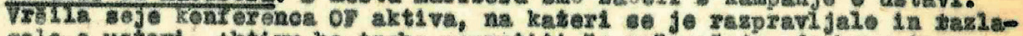
galo ustavi. Aktivi bo treba posvetiti ge ves paste, da bo ustavo dobzo razumel in jo znal razlagati. Glede ustave se pojavijajo predssen

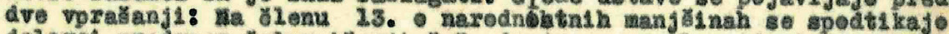
delavol predvaem šleleznidarji ces, da je nepravilno, da lmajo jemol

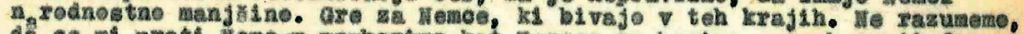

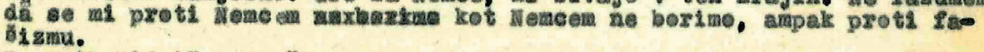

Tovert. Kidris : Memka manjsina pri nas ne bo imela nobane pravice, ker Je ne Dol

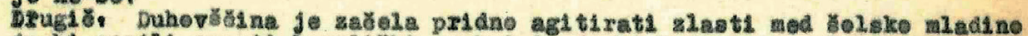
da bi soatli zvest1 kasolicki eerkvi in da bi hodili $v$ cerkev $k$ pouku

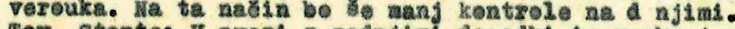

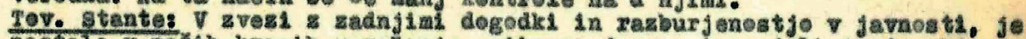
nastalo $\checkmark$ na $i \mathrm{~h}$ krogih vpramanje, otbroma dvon o tem, dali je dovolj

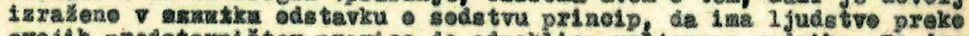
svojih predstavniftev pravico do odpokilea voljenega sodnika. Ta dvom

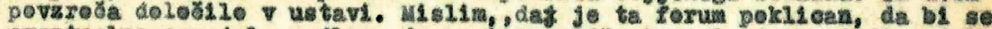

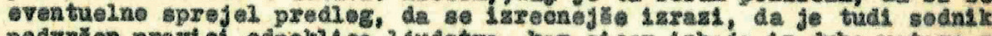
podvrsen pravi ed odpoklica Ijudstva, kax leox Izhaja $1 \mathrm{z}$ duha ustave game. Iz pravmih ozsxov misi $1 \mathrm{~m}$, ds bL bllajinestna tozadevna dopolnitev. 20v. Borgtrax, Na pobudo uinistrstva za 20kalni promet se je dine

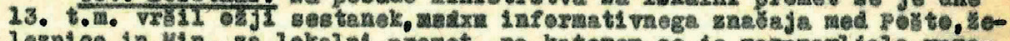
lemico in uin. za lokelns promet, na kateren se je raspravijale vora-

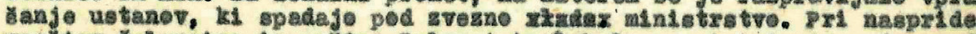
vpostev žleznd in posta. Delegat iz lokalnega ministratve je predle-

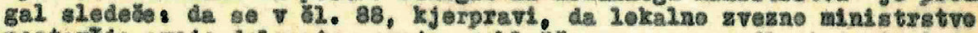
postavkja svoje delegate, svoje pooblaskance, po prediog dostavi doste vak..... pooblastenee naj bl ime velo federalno mini atrotve za proat in porto. Druga resolueija je bila, naj bi go porta in promet prenesia 12 gveznega winstrstte gregno republikensko ministratvo. V tem

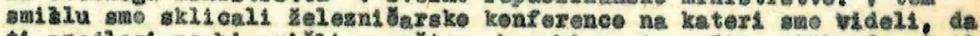

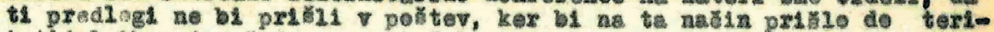
tobjalnih meja. gedar pa pri zolezniol ne more biti(da bl imell mejo

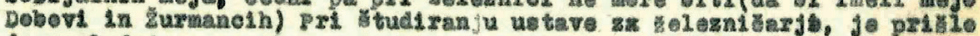
de naslednjega prediogs, da bl zvezno ministxstvo-žleznigio- imelo te
\end{abstract}

(Quelle: ARS, Bestand Boris Kidrič, AŠ 18, Protokol der Sitzung des Hauptkomitees der Befreiungsfront Ljubljana vom 15.12.1945) 
Die Zukunft der deutschen Minderheit in Slowenien wurde nach dem Kriege endgültig. Auf die Frage, welche Rechte die deutsche Minderheit in Slowenien nach dem Krieg haben wird, antwortete Boris Kidrič am 15. Dezember 1945 auf der Sitzung des Hauptkomitees der Befreiungsfront Ljubljana: „Die deutsche Minderheit wird keine Rechte haben, weil es sie nicht geben wird“(Jenuš 2016: 165-169). ${ }^{25}$

\section{Literatur}

BAŠ, Franjo (1989) Prispevki k zgodovini severovzhodne Slovenije. Maribor: Obzorja. BAUER, Otto (1907) Die Nationalitätenfrage und die Sozialdemokratie. Wien: Verlag der Wiener Volksbuchhandlung Ignaz Brand.

BENEDIK, Metod (Hrsg.) (2002) Lambert Erlich, Pariška mirovna konferenca in Slovenci 1919-1920. Ljubljana: Inštitut za zgodovino Cerkve pri Teološki fakulteti Univerze.

BIBER, Dušan (1966) Nacizem in Nemci v Jugoslaviji 1933-1941. Ljubljana: Cankarjeva založba.

BISTER Feliks (1990) „Delovanje dr. Antona Korošca od Majniške deklaracije do 1. 12. 1918.“ Zgodovinski časopis, 1, 73-90.

BISTER, Feliks (1995) Majestät, es ist zu spät. Anton Korošec und die slowenische Politik im Wiener Reichsrat bis 1918. Wien: Böhlau Verlag.

CVIRN, Janez (1998) „Nemško (avstrijsko) in slovensko zgodovinopisje o Nemcih na Slovenskem (1848 - 1941).“ In: D. Nećak (Hrsg.), 23-52.

ČOH, Mateja (2006) „Maribor v času druge svetovne vojne.“ Studia historica Slovenica, 2-3, 495-530.

ČUČEK, Filip (2006) „Kraji na Slovenskem Štajerskem in Maribor med leti 1750 in 1918." Studia historica Slovenica, 2-3, 281-402.

DOLENC, Ervin (2004) „Deavstrizacija v politiki, upravi in kulturi v Sloveniji““ In: D. Nećak (et al.) (Hrsg.), Slovensko-avstrijski odnosi v 20. stoletju. Slowenisch-österreichische Beziehungen im 20. Jahrhundert. Ljubljana: Oddelek za zgodovino Filozofske fakultete, 81-94.

FERENC, Mitja/Božo REPE (2004) „Nemška manjšina v Sloveniji med obema vojnama.“ In: D. Nećak (et al.) (Hrsg.) Slovensko-avstrijski odnosi v 20. stoletju. Slowenisch-österreichische Beziehungen im 20. Jahrhundert. Ljubljana: Oddelek za zgodovino Filozofske fakultete, 147-160.

FERENC, Tone (1968) Nacistična raznarodovalna politika v Sloveniji v letih 19411945. Maribor: Obzorja.

FERENC, Tone (1993) „Množično izganjanje Slovencev med drugo svetovno vojno.“ In: F. Šetinc (Hrsg.), Izgnanci: zbornik slovenskih izgnancev 1941-1945. Ljubljana: Delo, 17-40.

FERENC, Tone (1998) „Nemci na Slovenskem med drugo svetovno vojno.“ In: D. Nećak (Hrsg.), 17-23, 69-74.

25 ARS, Bestand Boris Kidrič, AŠ 18, Protokoll der Sitzung des Hauptausschusses der Befreiungsfront in Ljubljana vom 15.12.1945. 
GAČIĆ, Aleksandra/Gregor JENUŠ (2016) Znameniti Velenjčan Karel Verstovšek (1871-1923), zaslužni slovenski politik. Politična biografija: ob 145. obletnici rojstva. Velenje: Ustanova Velenjska knjižna fundacija, 50-55.

HARTMAN, Bruno (1989) Rudolf Maister. Ljubljana: Partizanska knjiga.

HARTMAN, Bruno (1998) Rudolf Maister, general in pesnik. Ljubljana: DZS.

JENUŠ, Gregor (2011a) Ko je Maribor postal slovenski. Iz zgodovine nemško-slovenskih odnosov v Mariboru od konca 19. stoletja in v prevratni dobi. Maribor: Znanstvenoraziskovalni inštitut dr. Franca Kovačiča.

JENUŠ, Gregor (2011b) „Slovenska pričakovanja in odzivi na odločitve velikih pet./ Les attentes Sloves et leurs réactions face aux décisions des Cinq Grands.“ In: A. Rahten/J. Šumrada (Hrsg.), Velikih pet in nastanek Kraljevine Srbov, Hrvatov in Slovencev./Les cinq grands et la création du Royaume des Serbes, Croates et Slovènes. Loka pri Mengšu: Center za evropsko prihodnost; Ljubljana: Znanstvenoraziskovalni center Slovenske akademije znanosti in umetnosti, 177-194, 417-436.

JENUŠ, Gregor (2013) „'Es gibt einen Meister über alle irdische Maister.' Avstrijski odzivi na Maistrov prevzem oblasti v Mariboru in na Spodnjem Štajerskem v letih 1918-1919.“ Arhivi, 2, 221-236.

JENUŠ, Gregor (2014) „Maribor ali ,Marburg an der Drau“? Spreminjanje nacionalne identitete mesta v prvi polovici 20. stoletja." Casopis za zgodovino in narodopisje, 4, 35-69.

JENUŠ, Gregor (2015) „Slovenci in velika vojna (1914-1918). Slovenska razdvojenost med zvestobo cesarju in željo po narodni avtonomiji.“ Studia historica Slovenica, 2, 301-319.

JENUŠ, Gregor (2016) „'Nemška manjšina pri nas ne bo imela nobene pravice, ker je ne bo!' (Boris Kidrič, 15. 12. 1945): komunistični obračun z Nemci na Slovenskem in uničenje nemške manjšine." In: M. Maučec/S. Granda (Hrsg.), Leto 1945 - 70 let potem. Ljubljana: Državni svet Republike Slovenije und Študijski center za narodno spravo, 154-169.

JENUŠ, Gregor (2017) „,'Ljubi Bog, kako varovati, česar ni; saj vendar pri vseh koncih in krajih sili v Mariboru slovenski značaj na dan!' Johann Schmiderer - zadnji mariborski župan avstrijske dobe." Studia Historica Slovenica, 3, 901-927.

JENUŠ, Gregor (2018) General Rudolf Maister in izgubljene priložnosti Slovencev po veliki vojni. Arhivalija meseca. $\mathrm{http}$ ///arhiv.arhiv-spletisc.gov.si/si/delovna_podrocja/razstavna dejavnost/arhivalija meseca november 2018/index.html\#c17946

JERIČ, Josip (1928) „Narodni svet.“ In: J. Mal (Hrsg.), Slovenci v desetletju 19181928. Zbornik razprav iz kulturne, gospodarske in politične zgodovine. Ljubljana: Slovenska matica, 144-159.

KARNER, Stefan (1978) „Das Land wieder deutsch machen.“ Profil, 10.10.1978, 51-54.

KARNER, Stefan (1998) Die deutschsprachige Volksgruppe in Slowenien, Aspekte ihrer Entwicklung 1939-1997. Klagenfurt: Hermagoras.

KARNER, Stefan (2000) „Die untersteirische Frage 1918/19.“ Die Kärntner Landsmannshaft, 9-10, 56-63.

KLEMENČCČC, Matjaž (2010) „Indigenous National/Etnic Minorities in the AlpsAdriatic-Pannonian Region, 1921-1938./Avtohtone narodne/etnične manjšine v alpsko-jadransko-panonskem prostotu, 1921-1938.“ In: S. Brezigar (Hrsg.), Treatises 
and documents/Razprave in gradivo. Journal of Ethnic Studies/Revija za narodnostna vprašanja, 62, 8-49.

KLEMENČIČ, Matjež (1994) „Die Slowenen und Deutschen im Lichte der sprachlichen Statistik in der Südsteiermark und in der Untersteiermark 1830-1991.“ In: Ch. Stenner (Hrsg.), Steirische Slowenen. Zweisprachigkeit zwischen Graz und Maribor. Graz: Alpen Adria Alternativ, 39-56.

KLEMENČIČ, Vladimir (1986) „Nemci v statistiki v jugoslovanski Sloveniji med obema vojnama.“"Zgodovinski časopis, 4, 465-470.

KOMAC, Miran (Hrsg.) (2007) Priseljenci. Študije o priseljevanju in vključevanju v slovensko družbo. Ljubljana: Inštitut za narodnostna vprašanja.

LIPUŠČEK, Uroš (2003) Ave Wilson. ZDA in prekrajanje Slovenije v Versaillesu 1919-1920. Ljubljana: Sophia.

LYNCH, Alan (2002) „Woodrow Wilson and the principle of "national self-determination': a reconsideration." Review of International Studies, 2, 419-436.

MAISTER, Rudolf (1934) „Prevzem mestne uprave v Mariboru, dne 2. januarja 1919.“ Kronika slovenskih mest, 3, 227-231.

MIKOLA, Milko (2007) Dokumenti in pričevanja o povojnih koncentracijskih taboriščih v Sloveniji. Ljubljana: Ministrstvo za pravosodje Republike Slovenije.

NEĆAK, Dušan (Hrsg.) (1998) Nemci na Slovenskem 1941-1955. Ljubljana: Znanstveni inštitut Filozofske fakultete Ljubljana.

OGRIZEK, Emica (2006) Sodni register Okrožnega sodišča Maribor 1898-1941. Trgovski register Maribor: Pokrajinski arhiv Maribor.

OSET, Željko (2010) „Nostrifikacija premoženja po prvi svetovni vojni s poudarkom na območju sodnega okraja Maribor." In: Ž. Oset/A. Berberih-Slana/Ž. Lazarević (Hrsg.), Mesto in gospodarstvo. Mariborsko gospodarstvo v 20. stoletju. Ljubljana: Inštitut za novejšo zgodovino und Maribor: Muzej narodne osvoboditve, 77-137.

PLETERSKI, Janko (1971) Prva odločitev Slovencev za Jugoslavijo. Politika na domačih tleh med vojno leta 1914-1918. Ljubljana: Slovenska matica.

PLETERSKI, Janko (1980) Politično preganjanje Slovencev v Avstriji 1914-1917. Viri 1. Ljubljana: Arhivsko društvo Slovenije.

POTOČNIK, Dragan (2003) Kulturno dogajanje v Mariboru med 1918 in 1941. Maribor: Litera.

POTOČNIK, Dragan (2008) Zgodovinske okoliščine delovanja generala Rudolfa Maistra na Štajerskem, Koroškem in v Prekmurju. Ljubljan: Koščak.

PUFF, Rudolf Gustav (1999) Maribor. Njegova okolica, prebivalci in zgodovina. Maribor: Obzorja.

RATEJ, Mateja (2006) „Kraji na slovenskem Štajerskem in Maribor v letih 19181941." Studia historica Slovenica, 2-3, 445-466.

RAHTEN, Andrej (2020) Po razpadu skupne države. Slovensko-avstrijska razhajanja od mariborskega prevrata do koroškega plebiscita. Celje/Celovec/Gorica: Mohorjeva družba.

REPE, Božo (1998) „Nemci na Slovenskem po drugi svetovni vojni.“ In: D. Nećak (Hrsg.) Nemci na Slovenskem 1941-1955. Ljubljana: Znanstveni inštitut Filozofske fakultete Ljubljana, 145-172. 
SCHNEEFUSS, Walter (1939) Deutschtum in Süd-Ost-Europa. Leipzig: Wilhelm Goldmann Verlag.

SCHWABE, Klaus (1971) Woodrow Wilson. Ein Staatsmann zwischen Puritanertum und Liberalismus. Göttingen/Zürich/Frankfurt a. M.: Muster-Schmidt.

SENEKOVIČ, Ivan (1936) „Sedemindvajseti januar 1919 v Mariboru.“ Kronika slovenskih mest, 3, 1, 59-64; 110-114.

STAVBAR, Vlasta (2017) Majniška deklaracija in deklaracijsko gibanje. Slovenska politika v habsburški monarhiji, od volilne reforme do nove države (1906-1918). Maribor: Založba Pivec.

SVOLJŠAK, Petra (2005) „Slovenci v primežu avstrijske cenzure.“ In: P. Vodopivec (Hrsg.), Velika vojna in Slovenci. Ljubljana: Slovenska matica.

SVOLJŠAK, Petra (2009) „Velika vojna in Slovenci.“ Studia historica Slovenica, 2-3, 297-316.

UDE, Lojze (1979) „Rudolf Maister. Ob 60-letnici bojev za severno slovensko mejo.“ Zgodovinski časopis, 1-2 (1979), 370-383.

WEHLER, Hans-Ulrich (1980) Nationalitätenpolitik in Jugoslawien. Göttingen: Vandehoeck und Ruprecht.

WINKLER, Wilhelm (1931) Statistisches Handbuch der europäischen Nationalitäten. Wien/Leipzig: Braumüller Verlag.

ZWITTER, Fran (1955) „Problem narodnega preroda pri Južnih Slovanih v Avstriji: legitimizem in narodnostno načelo."Zgodovinski časopis, Nr. 1-4 (1955): 162-169.

ZWITTER, Fran (1962) Nacionalni problemi v habsburški monarhiji. Ljubljana: Slovenska matica.

ŽERJAV, Gregor (1918) Ali so Ptuj, Celje, Maribor res nemška mesta? Nekoliko odgovora ptujskim, celjskim in mariborskim očetom ter nekaj statističnega orožja slov. podložnikom »nemških trdnjav«. Ljubljana: Narodna tiskarna.

ŽERJAV, Gregor (1917) [Autor angegeben als: Von einem Südslaven] Die nationale Abgrenzung im Süden. Ein Beitrag zur Realisirung der Selbstbestimmung der Völker Oesterreich-Ungarns. Zagreb: Hrvatska tiskarna.

\section{Archievbestände:}

ARS - Archiv der Republik Slowenien: Bestand Ude Lojze (SI AS 1193); Bestand Pokrajinska uprava za Slovenijo (SI AS 60); Bestand Republiški sekretariat za notranje zadeve SRS (SI AS 1931); Bestand Boris Kidrič (SI AS 537).

PAM - Landesarchiv Maribor: Bestand Mestna občina Maribor; Bestand Narodni svet za Štajersko; Bestand Okrožno sodišče Maribor.

\section{Zeitschriften:}

Deutsche Wacht (1917), (1918).

Die Neue Zeitung (1919).

Jutro (1922).

Marburger Zeitung (1917), (1918), (1941).

Mariborski delavec (1919). 
Nova doba (1919).

Pester Lloyd (1919).

Reichspost (1919).

Slovenec (1919).

Slovenski gospodar (1919), (1941).

Slovenski narod (1923).

Straža (1917), (1918).

Tabor (1922).

Wiener Allgemeine Zeitung (1919).

\section{Zusammenfassung \\ DIE VERGESSENE MINDERHEIT: ZUR GESCHICHTE DER DEUTSCHEN IN MARIBOR}

Im 20. Jahrhundert erlebte Maribor (Marburg an der Drau) zahlreiche Veränderungen seines öffentlichen Erscheinungsbildes. Dies gilt vor allem für die erste Hälfte des Jahrhunderts, als der Machtkampf zwischen der Deutschen und Slowenen im öffentlichen Leben und der damit verbundene Konflikt zwischen der deutschen und slowenischen Identität noch stark präsent waren.

Nachdem die Deutschen die Pariser Friedensverträge unterzeichneten, wurden sie zur Minderheit und verloren somit alle Privilegien der regierenden Nation in Slowenien. Trotz allem ermöglichten ihnen ihr Kapital und die Tatsache, dass sie die zahlreichste Minderheit waren, das „Überleben“. Ihre Hoffnungen, wieder an die Macht zu kommen, erfüllten sich Anfang des Zweiten Weltkrieges. Maribor/Marburg bzw. im weitesten Sinne Jugoslawien betrachteten bis 1941 stumm die Kämpfe zwischen den Weltmächten, die in ihrer Übermacht und Zielstrebigkeit über den hilflosen Nationen herfielen. Jugoslawien war unter großem Druck, denn es war ein strategisch wichtiger Punkt auf dem Balkan. Am Anfang schaffte Jugoslawien es, neutral zu bleiben. Die Realität änderte sich aber schnell, denn am 25. März 1941 trat das Königreich Jugoslawien in Wien dem Dreimächtepakt bei. Das Königreich Jugoslawien beugte sich so dem Druck der Achsenmächte und versuchte, mit dem Beitritt zum Pakt die Okkupation zu vermeiden. Die Unterzeichnung des Dreimächtepakts löste in Jugoslawien unterschiedliche Reaktionen aus. Trotz des Beitritts zum Pakt geschah alles anders, wie die Landesregierung es erwartete. Breite Massen der Bevölkerung waren nicht begeistert, dass Jugoslawien vor den Nazis niederkniete, und dies stiftete Unruhen. In der Nacht vom 26. auf den 27. März 1941 kam es zum Staatsstreich und der achtzehnjährige Thronfolger, Peter Karađorđević, kam an die Spitze des Landes. Schon am 27. März 1941, nur zwei Tage nach der Unterzeichnung des Dreimächtepakts und nach den Unruhen, setzten die Nazis Dr. Siegrid Uiberreither, den Gauleiter der Nationalsozialistischen Deutschen Arbeiterpartei (NSDAP) und den Staatsvertreter für die Steiermark als den zukünftigen Leiter der Zivilbehörde für die Untersteiermark ein. Er übernahm die Herrschaft über die Untersteiermark, die ihren Sitz in Maribor/Marburg hatte, am 
Ostermontag, d. h. am 14. April 1941. Nur eine Woche früher, am Palmsonntag, am 6. April 1941, begann ohne Kriegserklärung der Angriff auf Jugoslawien, der für immer das Erscheinungsbild Maribors/Marburgs änderte und das Schicksal der hier lebenden Deutschen besiegelte. Ihr Schicksal in Slowenien lässt sich am besten mit dem Zitat von Boris Kidrič vom Dezember 1945 beschreiben: „Die deutsche Minderheit bei uns wird keine Rechte haben, weil es sie nicht geben wird.“

Schlüsselwörter: Deutsche, Slowenen, transnationale Beziehungen, deutsche Minderheit, Untersteiermark

\section{Abstract \\ THE FORGOTTEN MINORITY. ON THE HISTORY OF THE GERMAN MINORITY IN MARIBOR}

In the $20^{\text {th }}$ century, Maribor frequently experienced a radical transformation of its public image. The latter is particularly true for the first half of the century, when the struggle between Germans and Slovenes for the supremacy over the city and the associated conflict between the Slovene and German identity was still very much present.

After the Germans signed the Paris Peace Treaties, they were placed in the position of a minority and lost most of the privileges they had had as the dominant ruling nation in Slovenia. Nevertheless, their cultural capital and the fact that they were the single most numerous minority in Slovenia, made it possible for them to "survive". Their hopes of regaining their power came true with the onset of World War II. In 1941, Maribor and in the broadest sense Yugoslavia was just a silent observer of fights between the world superpowers. They were fighting for their superiority and in order to achieve their goals, and took advantage of helpless nations. Yugoslavia came under major pressure, since it was a strategically important territory in the Balkans. However, at least at first, Yugoslavia managed to stay undecided. The reality, however, quickly changed, as the Kingdom of Yugoslavia signed the Tripartite Pact on 25th September 1941 in Vienna. With signing of the Pact, the Kingdom of Yugoslavia yielded under the pressure of the Nazi Block. It had hoped that it would not be occupied, since it had become part of the Tripartite Pact. The signing of the Pact prompted various reactions in Yugoslavia. The events that followed the signing were quite the opposite of what the authorities had expected. The population was dismayed when Yugoslavia bowed to the Nazis and riots started. In the night between 26th and 27th March 1941, the government was overthrown and the eighteen-year-old heir to the throne, Peter Karađorđević, wielded political power. On 27th March 1941, only two days after the signing of the Pact and the outbreak of riots, the Nazis appointed Siegfried Uiberreither, who was a Gauleiter of the National Socialist German Workers' Party (Nationalsozialistische Deutsche Arbeiterpartei (NSDAP) and National Deputy for Styria, the future head of the civil administration for Lower Styria. He took over the government, which had their headquarters in Maribor, on Easter Monday, i.e. on 14th April 1941. Only a week earlier, on Palm Sunday (December 6th), without declaration of war, began the attack 
on Yugoslavia, which utterly changed the face of Maribor and sealed the fate of Germans living here. Their fate is best illustrated by a quotation from Boris Kidrič from December 1945: "The German minority in Slovenia will have no rights, for there will be no German minority."

Keywords: Germans, Slovenes, Transnational Relations, German Minority, Lower Styria

\section{Povzetek \\ POZABLJENA MANJŠINA: K ZGODOVINI NEMCEV V MARIBORU}

Maribor je v 20. stoletju večkrat doživljal transformacijo svoje javne podobe. Slednje še zlasti velja za prvo polovico stoletja, ko je bila $v$ javnem življenju še vedno zelo močno prisotna borba med Nemci in Slovenci za oblast $v$ mestu, $\mathrm{s}$ tem pa je bil povezan konflikt med nemško in slovensko identiteto.

Potem ko so Nemci s podpisom pariške mirovne pogodbe bili potisnjeni v položaj narodne manjšine, so v veliki meri izgubili privilegije vladajočega naroda na Slovenskem. Kljub vsemu pa sta jim njihov kapital kakor tudi dejstvo, da so bili najštevilčnejša narodna manjšina na Slovenskem, omogočila „preživetje“. Njihovo upanje na ponovni vzpon se je obudilo s pričetkom druge svetovne vojne. Maribor (oziroma v najširšem smislu Jugoslavija) je do leta 1941 le nemo spremljal divjanje med svetovnimi velesilami, ki so se v svoji premoči in strmenju za dosego svojih ciljev zgrnile nad večinoma nemočnimi narodi. Jugoslavija je bila deležna številnih pritiskov, saj je predstavljala strateško ozemlje na Balkanu. Vendar je sprva uspela ostati neopredeljena. Kljub vsemu se je realnost hitro spremenila, saj je Kraljevina Jugoslavija 25. marca 1941 na Dunaju podpisala pristop $\mathrm{k}$ trojnemu paktu. Kraljevina Jugoslavija je s tem klonila pod pritiski nacističnega bloka in se $\mathrm{s}$ pristopom $\mathrm{k}$ trojnemu paktu poskušala rešiti pred osvojitvijo. Kljub pristopu pa so se dogodki odvijali v nasprotju s pričakovanji vrha države. Ljudske množice pristopa namreč niso pozdravile in pričeli so se nemiri. V noči s 26. na 27. marec 1941 je bil izveden državni udar, ki je na oblast postavil osemnajstletnega prestolonaslednika Petra Karađorđevića. Že 27. marca, torej le dva dni po podpisu pristopa $\mathrm{k}$ trojnemu paktu in izbruhu nemirov, so nacisti kot bodočega vodjo civilne uprave za Spodnjo Štajersko določili gaulajterja stranke Nationalsozialistische Deutsche Arbeiterpartei (NSDAP) in državnega namestnika za Štajersko dr. Siegfrieda Uiberreitherja. Slednji je oblast nad Spodnjo Štajersko, s sedežem v Mariboru, prevzel na velikonočni ponedeljek, 14. aprila. Le teden dni prej, 6. aprila 1941, se je na cvetno nedeljo brez vojne napovedi pričel napad na Jugoslavijo, ki je za vedno spremenil podobo Maribora in hkrati zakoličil usodo Nemcev, ki so v njem živeli. Njihovo usodo na Slovenskem najbolje opisuje izrek Borisa Kidriča decembra 1945: „Nemška manjšina pri nas ne bo imela nobene pravice, ker je ne bo.“

Ključne besede: Nemci, Slovenci, mednacionalni odnosi, nemška manjšina, Spodnja Štajerska 